\title{
EDITORIAL
}

\section{Editing the ERJ: an observational study}

\author{
K.F. Rabe and P.J. Sterk
}

W e know that we are usually the first to underline the importance of evidence for any claim made by authors submitting their work to our Journal, but at this point in our editorship of the European Respiratory Journal $(E R J)$, we thought it worthwhile to share with you some recent observations we have made.

Information that is not based on randomised trials can be very valid and has gained considerable attention recently. It is recognised as a credible form of research with the potential to reveal unexpected mechanisms of disease in general and to present unwanted side-effects of the intervention in question [1]. In essence, it is a form of reflection and this is what we as your Editors have been doing over the past 3 years.

\section{A GOOD CASE FOR GOOD CASES}

In case you have not already realised, we have been supporters of observational studies for quite some time, and regularly publish this form of information in the ERJ; case presentations and cases for diagnosis are prime examples. The Journal has a long history of presenting interesting observations (attention readers and connoisseurs of editorial strategies: don't worry, we will resist the temptation to cite them all at this point since this is not our intention when writing editorials) and we have continued to do this for some very good reasons. Together with Erik Berglund, who has been indispensable in this process for many years (and we simply dread the prospective that he might ever stop supporting us), and in contrast to some other journal editors, we believe that these cases are an important part of the Journal's content.

Whilst we do not have hard evidence to support this, we do think that our readers take a strong interest in these case studies and cases for diagnosis (as is suggested by on average 8,227 hits per month in these two categories on our ERJ website during the past year). Furthermore, such articles allow our Publications Office to fully demonstrate one of the ERJ's real strengths: its attractive layout and top-class illustrations.

One of the recognised strengths of observational studies is their value in detecting the unexpected, including adverse effects, and it is because of this that we ask for only truly novel findings in this category; many of you that we had to disappoint in the past by rejecting submitted manuscripts will have recognised this. But take a look for yourself: this month's case study is an excellent example of what we mean by novelty

CORRESPONDENCE: European Respiratory Journal, Chief Editor's Office, Dept of Pulmonology, C3-P, Leiden University Medical Center, Albinusdreef 2, P0 Box 9600, NL-2300, Leiden, The Netherlands. Fax: 31 715266927. E-mail: erj@lumc.nl and top quality, and we are certain that not only clinicians but also scientists will be excited when reading this [2].

\section{STATEMENT OF INTEREST AND THE TOBACCO INDUSTRY}

You may have noticed some recent changes in the Journal submission procedure. The instructions to authors indicate that statements of interest are now compulsory when submitting to the Journal, and we simply believe that this had to be done [3]. You may also have realised that, after discussion within the Publications Committee (chaired by the Past President of the European Respiratory Society (ERS)), we have agreed that we should not adopt the frequently used term "conflict of interest", but that we should simply emphasise the need for stating perceived competing interest when submitting materials to the Journal. By doing this, we hope to foster a mutual understanding that what we need most when publishing the ERJ is transparency. This is why, at present, we take notice of these statements, but have so far not precluded publication in the cases where researchers have listed a perceived conflict.

This principle has also applied in the past to research supported by the tobacco industry, but stay tuned because this is likely to change. We believe, and curiously the "case report" concerning Dr Rylander [4] clearly underlines the necessity to formulate a stringent policy, that research sponsored by the tobacco industry should not be accepted for publication by the ERJ in the future. For the same reasons, the ERS has also endorsed a policy of not allowing speakers or, in fact, any contributors with direct links to the tobacco industry to attend the Society meetings. Logically, this will also have to apply to any officer of the Society, including the editorial team. We believe as Editors that this process is necessary, and we hope that it will trigger further discussions. Perspectives have changed and, while it seemed acceptable years ago that research funding from tobacco industry could be directed towards a good cause, there is evidence that this assumption was partly incorrect [4].

The basic principle of our Society, to foster lung health, is clearly incompatible with the interests of the tobacco industry and this also applies to the Society's Journal. Manipulating individuals and influencing the presentation of their research is not acceptable. The American Journal of Respiratory and Critical Care Medicine made this move years ago under Alan Leff, and we think that we need to move in the same direction.

\section{GHOST WRITING, OR "WHO WROTE MY PAPER?"}

By careful observation of the flow of our submissions (around 1,500-1,600 per year), we have realised that, for various reasons, authors choose to involve other contributors or "ghost 
writers" when submitting material to our Journal. So far, we have treated this phenomenon as an unwanted side-effect of increasing competitiveness for survival of the peer-review process, but believe that the series of cases encountered over recent years should prompt a change in our policy. We realise that the contributions of ghost writers can vary, ranging from a draft of the first outline of a paper to being the only "real" author. In general, we do not think there is anything principally wrong with involving professional editorial help in writing a paper, but we also firmly believe that we and our readers need to know this. This is why, in future, we will ask you as submitting authors to provide this information and will list this under a "contribution of authors" section in the accepted paper. As with other statements of interest, the guiding principle is transparency, and several editors in the field and their scientific organisations have recognised this seemingly increasing trend of ghost writing and have agreed that journals need a uniform policy [5].

\section{DUPLICATE PUBLICATION}

Another of our observations during our 3 years in office concerns the various forms of duplicate publication that can occur [6]. We recognise that there is an occasional need to extend the analysis of previously published studies. Again, this is a matter of transparency. As long as this is clearly stated in the submission letter as well as the manuscript (with cross-referencing), it will be an editorial decision whether or not such a manuscript will be considered for publication. However, at the other end of the spectrum, we have encountered duplication of data without any mention or cross-referencing of the previous publication. This is simply unacceptable [6] and we do take action in those cases.

\section{THE RESPIRATORY JOURNALS' EDITORS GROUP}

Having observed the other respiratory journals from a distance and spoken to our fellow editors, we have realised that, despite some "healthy competition" in terms of recognition and impact factors, we share a lot of common interests and face the same challenges. For all our Journals, "open access publishing" is a topic of much debate as: we all want to position our Journals to meet readers' and citers' expectations; we know what impact factors mean to some of you; and we realise the necessity of safeguarding the integrity of research presented in our journals. This is why the editors of the leading respiratory journals (by impact) have started to meet to discuss the differing views and to communicate the principles under which we try to serve our communities. This process, which successfully started at the latest American Thoracic Society and ERS meetings in San Diego (CA, USA) and Copenhagen (Denmark), respectively, will undoubtedly harmonise our views on some of the burning issues listed above and will hopefully contribute to the transparency of the guiding principles of peer-review publishing in the respiratory field worldwide. We believe that you as readers and contributors of the $E R J$ are principally entitled to understand how the editorial process works and what the new challenges and potential threats to your journal are.

\section{EVIDENCE LEVEL D}

Admittedly, we are clearly biased, since we believe that by delivering this information to you, and reassuring you of the transparency in our editorial process, we can highlight the qualities of our Journal and encourage you to submit your best research to us. Is there any evidence that this helps improve the quality of the ERJ for the whole diverse group of readers? No, but communicative editorship has not harmed a journal so far either. Editing and publishing society journals in a traditional fashion is an increasing challenge to all involved. It is our probably completely unfounded, very subjective, and merely observational believe that the Journal is doing well and is not only well received by Journal designers (thanks for the award, by the way!) but by you, our readers. And you know what? It's still a lot of fun (evidence level D: consensus statement by your ERJ editors).

\section{REFERENCES}

1 Vandenbroucke JP. When are observational studies as credible as randomised trials? Lancet 2004; 363: 1728-1731.

2 Chung KF, Hew M, Score J, et al. Cough and hypereosinophilia due to FIP1L1-PDGFRA fusion gene with tyrosine kinase activity. Eur Respir J 2006; 27: 230-232.

3 European Respiratory Journal Instructions for Authors. http:/ /ERJ.ersjournals.com/misc/ifora.shtml.

4 Diethelm PA, Rielle J-C, McKee M. The whole truth and nothing but the truth? The research Philip Morris did not want you to see. Lancet 2005; 366: 86-92.

5 World Association of Medical Editors (WAME) Policy Statements. www.wame.org/wamestmt.htm\#ghost.

6 von Elm E, Poglia G, Walder B, Tramer MR. Different patterns of duplicate publication: an analysis of articles used in systematic reviews. JAMA 2004; 291: 974-980. 